Как можно видеть из представленной диаграммы темпы роста валового внутреннего продукта Российской Федерации за последние несколько лет практически всегда были ниже темпов роста мирового ВВП за исключением 2011 и 2012 года, когда темпы роста российского ВВП незначительно превышали мировые темпы роста.

В последние несколько лет можно видеть, что темпы роста российского ВВП значительно ниже темпов роста мирового ВВП. В 2018 году темпы роста российского ВВП будут в два раза ниже темпов роста мирового внутреннего валового продукта.

В заключении можно сделать следующие выводы:

по уровню ВВП по паритету покупательной способности Российская Федерация способна войти в пятерку крупнейших экономик мира, но не за счет развития производства, а за счет показателя инфляции и ослабления национальной валюты;

по показателю номинального валового внутреннего продукта Российская Федерация с трудом сможет удержать занимаемую на сегодняшний день двенадцатую позицию, потому что по показателям темпам роста ВВП Россия в два раза проигрывает мировым темпам роста валового внутреннего продукта;

по прогнозам темпы роста валового внутреннего продукта Российской Федерации в ближайшие шесть лет не превысят уровень в $2 \%$, даже при наметившейся тенденции роста цен на нефть, а, следовательно, превысит показатель темпов роста мирового ВВП не смогут.

$$
* * *
$$

1. В ближайшие 6-7 лет Россия может войти в число пяти крупнейших экономик мира. [Электронный pecypc]. https://www.finam.ru/analysis/newsitem/v-blizhaiyshie-6-7-let-rossiya-mozhet-voiyti-v-chislo-pyatikrupneiyshix-ekonomik-mira-20180522-145732/ (Дата обращения: 31.05.2018).

2. ВВП России по годам. [Электронный ресурс] http:/global-finances.ru/vvp-rossii-po-godam/ (Дата просмотра 31.05.2018)

3. Буньковский Д.В. О проявлениях теневой экономической деятельности. Аллея науки. 2017. Т. 2 . № 15. C. 285-288.

4. Темпы роста мирового валового продукта. [Электронный ресурс] http://www.ereport.ru/graph/gdpworld.htm (Дата просмотра 31.05.2018)

5. ВВП России в 2018 году. [Электронный ресурс] http://2018god.net/vvp-rossii-v-2018-godu/ (Дата просмотра 31.05.2018)

\title{
Батаев A.B.
}

\section{Последствия повышения пенсионного возраста в Российской Федерации}

Санкт-Петербургский политехнический университет Петра Великого (Россия, Санкт-Петербург)

doi:10.18411/lj-06-2018-18

idsp: 000001:lj-06-2018-18

\section{Аннотация}

В статье проводится анализ средней продолжительности жизни мужчин и женщин в Российской Федерации, производится сравнительная оценка дожития между мужчинами и женщинами, оцениваются последствия повышения пенсионного возраста для мужчин и для женщин.

Ключевые слова: пенсионная реформа, пенсионный возраст, средний возраст жизни для мужчин и женщин, Российская Федерация.

В середине 2018 года правительство Российской Федерации объявило о начале очередной пенсионной реформы, направленной на повышении пенсионного обеспечения пожилых жителей страны. Суть которой заключается в повышении пенсионного возраста для мужчин до 65 лет, а для женщин до 63 лет. За счет повышения пенсионного возраста предполагается высвобожденные средства направить на повышение пенсионного 
обеспечения нынешних пенсионеров, так в 2019 году предполагается повышение пенсий в среднем на 12000 рублей в год.

С одной стороны, получается поставлена благая цель бороться с бедностью населения Российской Федерации, а с другой возникает ряд вопросов по поводу повышения пенсионного возраста.

Если рассмотреть среднюю продолжительность жизни мужчин и женщин, то получается следующая картина. В 2017 году средняя продолжительность жизни составляла у женщин 77,6 лет, а средняя продолжительность жизни у мужчин составляла 66,8 лет (рис. 1). [1-5]

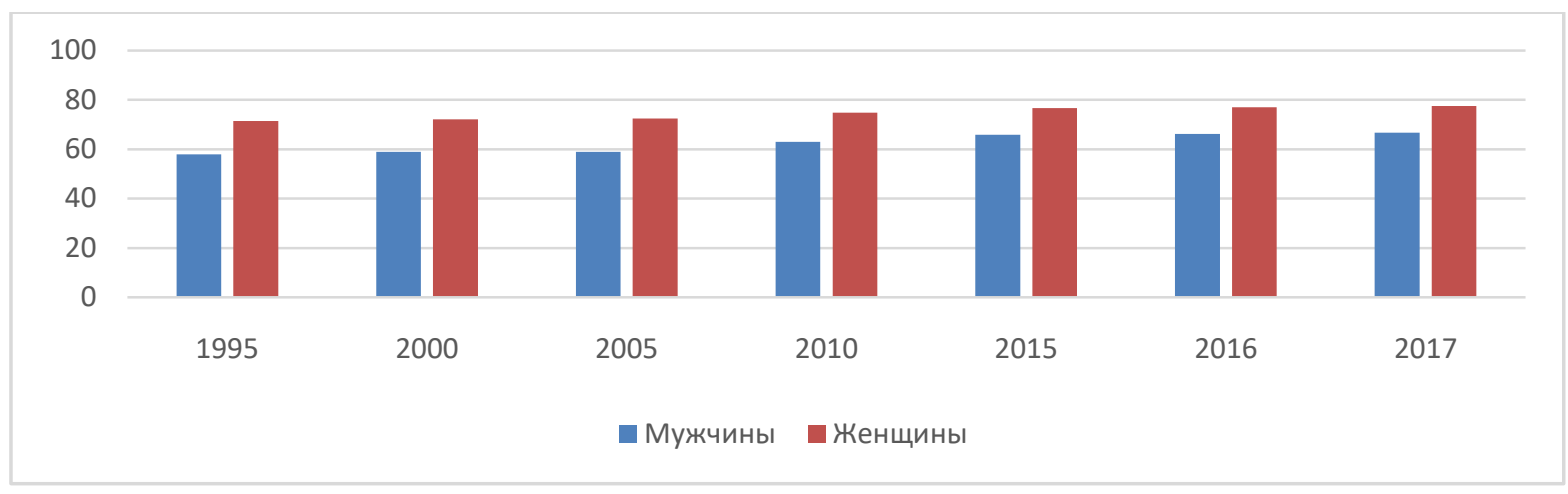

Рис. 1 Динамика изменения средней продолжительности жизни мужчин и женщин в Российской Федерации, лет.

При повышении пенсионного возраста для мужчин до 65 лет средняя продолжительность дожития на пенсии для мужчин составит 1,8 лет, а для женщин 14,6 лет. Разница между средней продолжительностью дожития на пенсии между мужчинами и женщинами составляет в 8,1 раза. Встает закономерный вопрос почему повышение пенсионного возраста для мужчин приводит фактически к сравниванию средней продолжительности жизни мужчин и выходом на пенсию. При таких условиях необходимо хотя бы не увеличивать пенсионный возраст у мужчин, а оставить на прежнем уровне, чтобы мужская половина смогла прожить хотя бы 6-7 лет на пенсии.

Вопрос о повышении средней продолжительности жизни мужской части населения Российской Федерации кажется достаточно сомнительным за семь лет средняя продолжительность жизни мужчин увеличилась всего на 3,6 лет, а за период с 2016 года по 2017 лет увеличение произошло всего на 0,5 года. Фактически рост средней продолжительность жизни мужчин замедляется и при нынешних условиях медицинского обслуживания вскоре совсем остановится.

В заключении можно сделать следующие выводы:

повышение пенсионного возраста для мужчин до 65 лет, а для женщин до 63 лет приведет к увеличению разницы между средним временем дожития на пенсии для мужчин и для женщин с 3,3 раза до 8,1 раза;

увеличение пенсионного возраста для мужчин до 65 лет приводит к фактическому уравниванию среднего возраста жизни мужчин с возрастом выхода на пенсию, что означает, что мужская часть населения Российской Федерации на пенсии жить не будет, потому что увеличение среднего возраста жизни мужчин начинает замедляться, так за период с 2010 по 2017 год повышение составило всего около 6\%, а при современных условиях медицинского обслуживания, связанного с сокращением медицинского персонала, ростом платных услуг, фактически останется на одном уровне, а в худшем может даже и снизится.

$$
* * *
$$

1. Средняя продолжительность жизни в России 2017: мужчины и женщины. [Электронный ресурс]. https://danetnavernoe.com/srednyaya-prodolzhitelnost-zhizni-v-rossii-muzhchin-i-zhenshhin (Дата обращения: 30.06 .2018$)$. 
2. Сколько в среднем лет живут мужчины и женщины в России: таблица по регионам на 2017 год. [Электронный pecypc]. https://calypsocompany.ru/pensii-2018/skolko-v-srednem-let-zhivut-muzhchiny-izhenshhiny-v-rossii-tablica-po-regionam-na-2017-god (Дата обращения: 30.06.2018).

3. Мужчины vs женщины: как менялась средняя продолжительность жизни в России? [Электронный pecypc]. http://takovzakon.ru/muzhchiny-vs-zhenshhin-kak-menjalas-srednjaja-prodolzhitelnost-zhizni-vrossii/ (Дата обращения: 30.06.2018).

4. Почему мужчины в России так часто не доживают до пенсии? [Электронный ресурс]. https://ura.news/articles/1036275372 (Дата обращения: 30.06.2018).

5. Демографический контекст повышения возраста выхода на пенсию. [Электронный ресурс]. https://www.hse.ru/news/expertise/220988047.html (Дата обращения: 30.06.2018).

\section{Каваев 3.Г., Бижанова Е.М. \\ Анализ рынка промышленного производства России}

ФГБОУ ВО «Пензенский государственный университет»

(Россия, Пенза)

doi:10.18411/lj-06-2018-19

idsp: 000001:lj-06-2018-19

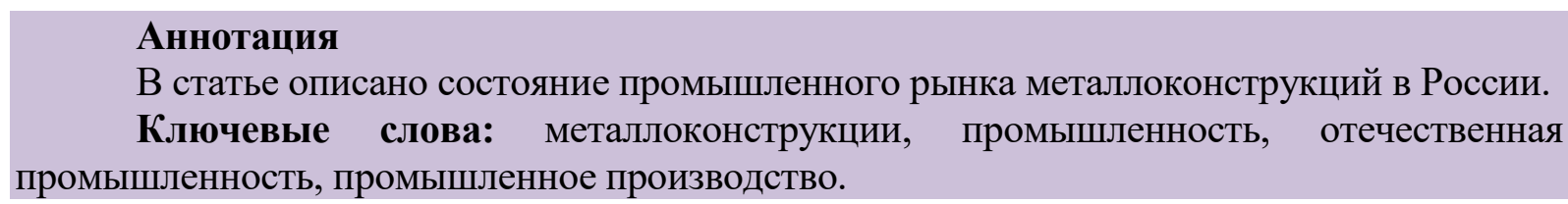

\section{Abstract}

The article describes the state of the industrial market of metal structures in Russia.

Key words: metal structures, industry, domestic industry, industrial production

Промышленное производство России в 2017 г. В 2016 году против России начали вводиться санкции странами ЕС и США, за чередой таких решений последовало резкое снижение экономических показателей страны, а экономические воздействовали на факторы внутри страны . По итогам 2017 года: экономика России пребывает в состоянии не только стагнации, от которой при отсутствии необходимых стране структурных перемен, но находится на пути к упадку.

Следствием выше перечисленных политических манипуляций было выяснено, что индекс промышленного производства в этом году упал с 102, 6 (показатель 2017 г.) до 99,9 \%, таким образом, объем промышленного производства в 2017 году сократился на 0,1 \% от предыдущего. Однако промышленное производство - это показатель, включающий в себя не только индекс добывающей промышленности, но и обрабатывающей, и производство электроэнергии. Однако единственным направлением, по которому Россия в предыдущем году немного улучшила свои показатели, стала добыча полезных ископаемых. Она выросла на 1,2 \%, в то время как оставшиеся 2 показателя упали на 0,6 $\%$ и $0,7 \%$. По всей видимости, рост добычи должен был компенсировать снижение стоимости нефти, либо компенсировать какую-то часть потерянных денежных ресурсов.

Но если говорить в целом, то снижение объема производства промышленной продукции связано не только со снижением инвестиций в основной капитал, но и их оттоком в большей степени, как за счет внутренних источников, так и за счет внешних инвестиций.

Однако, несмотря на всю ситуацию в стране, мы видим, что металлические конструкции продолжают широко применяться при строительстве жилых домов, объектов сельскохозяйственного назначения, промышленных и не промышленных зданий, спортивных сооружений и торговых комплексов, а также опор ЛЭП, объектов транспортной инфраструктуры (мостов, тоннелей, путепроводов, эстакад) и башен сотовой связи. С началом экономического кризиса, сопровождающегося снижением 